\title{
Zoonoses parasitárias veiculadas por alimentos de origem animal: revisão sobre a situação no Brasil
}

\section{Foodborne parasitic zoonosis: a review of the situation in Brazil}

\author{
Gabriel Augusto Marques Rossi 1 \\ Ana Maria Centola Vidal Martins ${ }^{2}$, Luiz Francisco Prata'
}

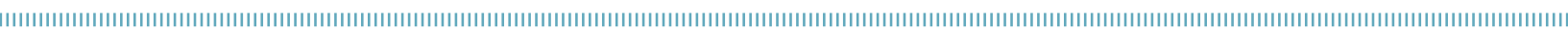

RESUMO: O Brasil se destaca na produção mundial de alimentos de origem animal, sendo que cada vez mais os mercados consumidores buscam alimentos seguros e inócuos para a saúde. Nesse contexto, torna-se fundamental a prevençáo das zoonoses, que podem ser transmitidas através dos alimentos de origem animal, que muitas vezes são consumidos sem o devido preparo ou por populaçôes mais vulneráveis. Nesta revisão bibliográfica, serão abordadas importantes enfermidades parasitárias de caráter zoonótico que ocorrem atualmente pela via de transmissão alimentar: a toxoplasmose, o complexo teníase-cisticercose, criptosporidiose, anisacose, difilobotriose e triquinelose.

PALAVRAS-CHAVE: zoonoses; enfermidades parasitárias; alimentos de origem animal.
ABSTRACT: Brazil is one of the most important countries in the production of animal source foods, and the consumers are looking for safe and innocuous products for health. In this context, it is necessary to prevent zoonosis that can be transmitted by animal source foods, which are sometimes consumed without proper cooking or made by vulnerable populations. On this review, important parasitic zoonotic diseases will be covered, which currently occur by this transmission route: toxoplasmosis, taeniasis-cysticercosis complex, cryptosporidiosis, anisakiasis, diphyllobothriasis and trichinosis.

KEYWORDS: zoonosis; foodborne parasitic diseases; foods of animal origin. 


\section{INTRODUÇÃO}

O Brasil possui grande potencial para a produçáo de alimentos, sejam estes de origem animal ou vegetal. Apenas no ano de 2011 foram abatidos 28,814 milhóes de bovinos, 5,269 bilhōes de frangos e 34,862 milhôes de suínos. Ainda, foram produzidas 2,56 bilhóes de dúzias de ovos de galinha e comercializados mais de 20 milhóes de litros de leite (IBGE, 2012).

Para aprimorar a qualidade desses produtos comercializados, tornou-se importante a prevenção da ocorrência de Doenças Transmitidas por Alimentos (DTA). Os fatores que contribuem para as DTA sáo: o crescente aumento das populações, a existência de grupos populacionais vulneráveis ou mais expostos, o processo de urbanizaçáo desordenado e a necessidade da produção de alimentos em larga escala, assim como o deficiente controle dos órgáos públicos e privados no tocante à qualidade dos alimentos ofertados às populaçóes, a utilização de novas modalidades de produção, as mudanças de hábitos alimentares, as mudanças ambientais e a globalização (BRAsIL, 2010).

Algumas das doenças veiculadas por alimentos são consideradas zoonoses, ou seja, ocorrem devido à interação entre os humanos e os animais, seus produtos e ambientes, podendo ser de origem viral, bacteriana ou parasitária. Em relaçáo ao último grupo, as doenças de veiculação alimentar mais importantes são toxoplasmose, complexo teníase-cisticercose, anisacose, difilobotriose, triquinelose e criptosporidiose (PrATA, 1999).

\section{Toxoplasmose}

A toxoplasmose é uma zoonose de distribuição mundial, causada pelo protozoário sarcocistídeo Toxoplasma gondii, parasita intracelular obrigatório. Os hospedeiros definitivos desse parasita são os felídeos, enquanto como hospedeiros intermediários podem ser listadas diversas espécies de vertebrados homeotérmicos, da ordem de 300 espécies de mamíferos, entre elas o homem e 30 espécies de aves (Dubey et al., 1970), afetando os sistemas reprodutivo, ocular, muscular e nervoso. Em Saúde Pública, T. gondii possui importância por causar graves desordens fetais e neonatais em humanos, além de prejuízos à saúde de crianças, idosos e adultos imunocomprometidos, interferindo na saúde das populações (PINTo et al., 2009).

Apresentam-se em três estádios principais: oocisto, taquizoíto e bradizoíto. Os taquizoítos são responsáveis pela fase aguda da infecção, enquanto os bradizoítos podem se agrupar e formar cistos teciduais intracelulares, podendo ser encontrados nas vísceras, cérebro, musculatura cardíaca e esquelética No ciclo evolutivo, os gatos eliminam pelas fezes os oocistos por até aproximadamente três semanas após a ingestão de qualquer dos estágios do parasita, onde realizará a reprodução assexuada que dará origem ao oocisto; este terá a esporulação fora do corpo do animal, de 1 a 5 dias após a eliminação (Dubey et al., 1970; Hill et al., 2005).
As três principais vias de transmissão são a ingestão de carne crua ou mal cozida, contendo cistos do parasita nos tecidos; ingestão de oocistos presentes no solo; e locais onde os felinos defecam, que podem ser carreados por vetores, pela água e por alimentos, com destaque para as hortaliças; assim como a via transplacentária (BRASIL, 2002).

Vários têm sido os fatores associados à infecção toxoplásmica, como o consumo de carnes mal passadas, leite caprino não pasteurizado e água não tratada (Jones et al., 2009).

Esse protozoário já foi encontrado no leite de diversas espécies animais, porém, apenas o consumo de leite caprino por humanos foi associado à transmissão da enfermidade, (CASTro, 2006), enquanto o leite de bovinos não apresenta importância epidemiológica (Dubey, 1986). O consumo de carnes ou derivados crus tem sido a principal via de transmissão para os humanos, sendo que as de ovinos, caprinos, suínos e equinos têm maior importância, por normalmente apresentarem maior frequência de cistos teciduais, enquanto as de bovinos e aves comerciais possuem menor relevância (Tenter et al., 2000). Segundo Da Silva et al. (2004), a carne suína é a principal fonte de infecção de toxoplasmose para o homem, pois os cistos podem permanecer viáveis por 171 dias na carne (Dubey et al., 1984). Alerta-se, ainda, para o consumo de ostras (Crassostrea rhizophorae) cruas ou mal cozidas, pois são capazes de filtrar e reter oocistos viáveis do parasita. Assim, podem ser uma via de transmissão potencial para humanos (EsMERINI, 2009; JoNes et al., 2009).

A enfermidade apresenta-se, normalmente, de forma crônica, porém, já foram relatados surtos de toxoplasmose aguda no Brasil, como o ocorrido em 1997, em Bandeirantes, no Paraná, acometendo 17 indivíduos que tinham consumido quibe cru preparado com carne ovina (BonAmetTi et al., 1997). No mesmo Estado, no município de Santa Isabel do Ivaí, entre os anos de 2001 e 2002, cerca de 600 pessoas apresentaram sintomas compatíveis com a toxoplasmose, das quais 426 apresentaram sorologia sugestiva de infecção aguda pelo parasita, com o mesmo recuperado posteriormente da água. Este foi o maior surto de toxoplasmose em humanos já registrado no mundo (BrasiL, 2002).

Também foi relatado um surto intrafamiliar, em 2005, no estado do Rio Grande do Sul, acometendo 10 indivíduos. Neste caso, o consumo de "copa" (embutido de carne suína) comercial esteva associado à ocorrência (BRAsIL, 2006). Outro surto, ocorrido em 2006, foi relatado acometendo 26 pessoas que tinham participado de uma festa, em Anápolis (GO), e a possível via de transmissão foi o consumo de quibe cru (BrasiL, 2007). Há também relatos de surtos em outros países, como os ocorridos na Coreia devido ao consumo de carne suína (CHOI, 1997).

A prevalência dessa enfermidade no Brasil é muito variável. Em estudo realizado por Araujo; Souza, em 1996, com suínos em abatedouros da regiâo de Erechim (RS), verificaram-se que $7,3 \%$ dos animais estavam infectados. Em outro estudo 
realizado no Brasil, foi encontrada prevalência de 32,34\% de bovinos infectados por Toxoplasma gondii destinados ao abate na região de Londrina (PR) (Marana et al., 1994). Nessa mesma regiáo, também foram avaliadas amostras de musculatura suína e de cérebros comercializadas em açougues, obtendo prevalência da infecção em 19,66\% e 22,22\% das amostras, respectivamente (NAVARRO et al.,1992).

Em São Paulo, utilizando animais de produção, observou-se taxa de prevalência da infecção toxoplásmica em 31,0\% dos ovinos, em $17,0 \%$ dos caprinos, em $11 \%$ dos bovinos e em $0 \%$ das aves comerciais analisadas (Meirelles et al., 2003). Outro estudo realizado em 2011, por Luciano et al., em frigoríficos de dois municípios do estado do Rio de Janeiro, foram observados $1,96 \%$ e 7,64\% de bovinos e suínos infectados, respectivamente, destacando a potencialidade de transmissão via consumo de carnes em nosso país.

Alerta-se, ainda, para o comércio ilegal de produtos de origem animal, pois em Belém (PA) foi diagnosticada a prevalência de anticorpos contra $T$. gondii de $50 \%$ nos suínos destinados ao abate sem inspeção sanitária (Freitas, 2009), assim como em amostras de carnes secas e salgadas comercializadas regionalmente (Jones; Dubey, 2012).

Ainda, o consumo de carne suína e de aves produzidas em sistemas orgânicos proporciona maior risco de infecção, pois os animais săo criados de forma mais extensiva, tendo acesso a ambientes externos que podem conter oocistos dos parasitas (Jones; Dubey, 2012). Ressalta-se, ainda, a importância do fornecimento de água adequado, pois diversos surtos vêm sendo relatados com essa fonte de infecção. A detecção do oocisto do parasita na água é difícil, e ainda não existem métodos padronizados para tal finalidade (DuBEY, 2004), apesar de a legislaçáo vigente exigir ausência de ovos, cistos ou oocistos em água destinada ao consumo humano.

Apesar de ser uma importante zoonose de elevada prevalência, que pode ser veiculada pelos alimentos após a mudança das características dos produtos comercializados, mais estudos são necessários, visto que os processos de conservação aplicados muitas vezes são capazes de impedir a transmissão dessa enfermidade, como o congelamento e a injeção de salmoura em frangos e o cozimento adequado de carnes; o congelamento considerado o método mais eficaz (Jones; DubeY, 2012; Ueno, 2005).

Também é recomendada a implantação das Boas Práticas Agrícolas (BPA), um conjunto de medidas que define práticas de higiene que podem ser adotadas nas propriedades para evitar a ocorrência de enfermidades, incluindo as zoonóticas, como a toxoplasmose. Essas propriedades costumam fazer parte de nichos seletos de mercado, como exportação à União Europeia, agregando valor aos seus produtos e contribuindo para a melhoria dessas cadeias produtivas (Jones; Dubey, 2012; VALLE, 2011).

KiJSLTRA, em 2009, afirmou ainda não existir um método de diagnóstico aplicável e padronizado para a detecção de
Toxoplasma gondii na carne dos animais, recomendando a prevenção da enfermidade na própria produção dos animais, através da implantaçấo de programas de monitoramento de enfermidades dos rebanhos, para evitar a infecçáo ou, para quando presente, destinar a um tratamento adequado. Porém, já estão disponíveis métodos de diagnóstico para a ocorrência dessa enfermidade em carnes, como o teste de ELISA, o Teste de Aglutinação Modificada e o PCR com captura magnética do DNA, que podem ser utilizados em laboratórios de controle de qualidade; o último, ainda, permite quantificar os taquizoítos, contribuindo para a inocuidade doa alimentos produzidos (Mecca et al., 2011; Villena, 2012; Opsteegh et al., 2010).

Para a prevenção dessa enfermidade, deve-se evitar a presença de felinos próximos às áreas de criação dos animais; evitar o consumo de alimentos de origem animal crus ou mal cozidos; eliminar as fezes de gatos de forma segura, evitando a esporulação em áreas domiciliares; proteger caixas de areia públicas para que gatos não defequem, evitando a presença do oocisto no ambiente em que crianças brincam; lavar as máos corretamente após manipulaçáo de carnes ou de solo; evitar o contato de grávidas com gatos; e lavar e higienizar corretamente frutas e verduras antes do consumo (BRASIL, 2010; ReY, 2002).

\section{Complexo teníase-cisticercose}

Segundo Almeida et al. (2006), a cisticercose é a zoonose mais frequentemente diagnosticada em abatedouros, assim como a principal causa de condenação de carcaças de bovinos abatidos, causando perdas econômicas associadas à produção de alimentos, além de diminuir o valor de seus produtos.

No complexo, os cestódeos da família Taeniidae, Taenia saginata e Taenia solium têm como hospedeiro definitivo exclusivamente os humanos. Os hospedeiros intermediários, infectados por meio da ingestão de ovos, são, respectivamente, os suínos e os humanos, para a Taenia solium, e os bovinos para a Taenia saginata, nos quais serão formados os cisticercos (SANtos; Barros, 2009).

Humanos adquirem a teníase através do consumo de carne crua ou mal passada contendo cisticercos, podendo ainda portar-se como hospedeiro intermediário e desenvolver doença de maior gravidade, a cisticercose, por meio do consumo de ovos da Taenia solium presentes em frutas e hortaliças ingeridas sem higienização. Os animais, por sua vez, sáo infectados ao pastarem e consumirem água contaminada (SANTOS; Barros, 2009).

A literatura aponta diversos fatores de risco para a infecção da cisticercose aos bovinos, como a presença de linhas rodoviárias ou estacionamento de veículos próximos às pastagens, atividades de lazer em volta das propriedades, origem da alimentaçâo fornecida, presença de atividades recreativas que possam atrair visitantes às propriedades (FLÜTSCH et al., 2008) 
e qualidade da água a qual os animais têm acesso (Allepuz et al., 2009; Boone et al., 2007).

Outro fato epidemiológico que deve ser levado em consideração é a utilização de esgotos urbanos como adubo orgânico agrícola. Quando contaminados com ovos de Taenia saginata viáveis, devido à utilização de tratamentos ineficazes, podem causar surtos de cisticercose nas propriedades produtoras de bovinos (CABARET et al., 2002).

A ocorrência da cisticercose bovina no Brasil é variável nas diversas regióes do país, sendo aparentemente maior nas regiôes Sudeste, Sul e Centro-oeste; porém, sua ocorrência é observada em todas as regióes (Dutra et al., 2012; Rossi et al., 2014).

Em 2003, FukUdA; PraTA, ao avaliarem carcaças de bovinos em frigoríficos sob o Serviço de Inspeção Federal (SIF) do Estado de São Paulo, obtiveram prevalência média de 4,28\% no período de 1980 a 2001. Em um estudo conduzido por Costa et al. (2012), obtiveram-se 3,23\% de prevalência em um abatedouro no mesmo estado. Já Oliveira et al., em 2010, encontraram índices variando entre 0,89 e 1,1\% para cisticercose bovina entre 2006 e 2009, em um matadouro localizado no Triângulo Mineiro. Enquanto isso, no Mato Grosso, houve baixa prevalência, de apenas $0,063 \%$, dos bovinos avaliados (Lima et al., 2011), que podem estar relacionadas com a densidade populacional e a urbanização dos Estados, além dos índices de saneamento básico.

Essa enfermidade acarreta grandes perdas econômicas, pois, quando presente durante a inspeção "post-mortem", as carcaças e vísceras poderấo ser condenadas total ou parcialmente, ou destinadas a tratamento térmico ou pela salga, segundo o regulamento da Inspeção Industrial e Sanitária dos Produtos de Origem Animal. A inspeção sanitária das carnes é uma das medidas efetivas para o controle do complexo, por reduzir a possibilidade do consumo de carne de animal infectado, sendo necessário o conhecimento dos locais de predileção da formação dos cisticercos (SANTos et al., 2001).

De acordo com Organizaçáo Mundial da Saúde Animal (OIE, 2008), a inspeção sanitária de carnes detecta apenas de 20 a 50\% dos animais infectados, devido às infecçôes discretas, que tornam a detecção difícil. Através da utilização de métodos de infecção experimental, SCANDRETT et al. (2009) avaliaram os locais de predileção dos cisticercos em bovinos e observaram maior densidade de cisticercos no coraçáo, diafragma, língua, músculos masseteres, pterigoides, então confirmando o perfil que sustenta a rotina da inspeção sanitária (Brasil, 1952; OIE, 2008).

O congelamento é o método mais eficaz e comumente empregado em carcaças tratáveis, estimado, na época, em R \$ 65,17 por animal (Fukuda; Prata, 2003). Ainda, segundo, Almeida et al. (2002), o impacto da ocorrência da cisticercose em bovinos é de US $\$ 420$ milhóes anuais na América do Sul, decorrentes das perdas econômicas associadas à produção de alimentos.
Para prevenir as enfermidades veiculadas por alimentos, de acordo com as normas internacionais harmonizadas e acordadas em 2000, o Ministério da Agricultura, Pecuária e Abastecimento instituiu, através da Portaria no 46, de 10 de fevereiro de 1998, a adoção do Sistema de Análise dos Perigos e Pontos Críticos de Controle (APPCC) no Brasil, considerado como pré-requisito para a exportação de carnes. Um dos principais pontos críticos de controle desse complexo é a produçáo animal, através das Boas Práticas Agrícolas (Rossi et al., 2014), que possuem recomendação da FAO, OMC e Codex alimentarius.

Para evitar a disseminaçáo desse importante problema de saúde pública, devem-se desenvolver trabalhos educativos em escolas e comunidades, conscientizando as pessoas a viverem com bons hábitos de higiene; a inspeção sanitária de carnes, reduzindo perdas financeiras e dando segurança ao consumidor; cuidados na etapa de criação dos animais, como impedir seu acesso a fezes e água contaminada (KyvsgaARD et al., 1991; Rossi et al., 2014) e saneamento básico para destinaçáo correta de dejetos (BrasIL, 2010).

\section{Criptosporidiose}

Essa enfermidade é causada pelo protozoário Cryptosporidium parvum, ocorrendo de forma assintomática ou caracterizada por diarreia, cólicas abdominais, anorexia, vômito, desidratação, náusea, tosse e febre. As diversas espécies do gênero Cryptosporidium acometem uma vasta gama de animais, porém, só $C$. parvum é conhecido por infectar humanos. O oocisto do agente pode ser transmitido pela água, solo, alimentos e superfícies contaminadas por fezes através da via fecal-oral para novos hospedeiros (CVE, 2002; MoriarTy et al., 2005).

No estado de São Paulo, surtos de criptosporidiose vêm sendo notificados, principalmente em creches com crianças de até quatro anos de idade, com um percentual de 1,3\%, no ano 2001, entre os surtos notificados (DDtha, 2002). Já foram relatados diversos surtos da enfermidade oriundos do consumo de produtos de origem animal, um deles ocorrido na Austrália, acometendo oito crianças cuja via de transmissão foi o consumo de leite de vaca cru (HARPer et al., 2002).

Um estudo realizado em Recife, avaliando hortaliças comercializadas em feiras, encontrou esse coccídeo em 12\% das amostras (Silva et al., 2005). Cryptosporidium sp. também já foi encontrado em bivalves marinhos, inclusive em mexilhóes destinados à alimentaçáo humana, alertando para um risco à saúde pública através do consumo desses moluscos crus ou cozidos inadequadamente (Hipolito et al., 2006).

Os métodos para detecção dessa parasitose ainda necessitam ser aprimorados, visto que os oocistos se encontram em pequenas quantidades nos alimentos. As técnicas moleculares baseadas na PCR são as mais indicadas, em vez da microscopia, porém, muitos estudos ainda são necessários para aprimorar e validar essa metodologia como ferramenta de açáo para 
um plano APPCC nas indústrias (Smith; Nichols, 2010). Além da necessidade de controlar essa enfermidade devido ao seu impacto na saúde pública, ela acarreta em perdas produtivas e, consequentemente, financeiras, devido ao menor peso de carcaça em animais abatidos de propriedades onde a enfermidade está presente (SweEny et al., 2011).

A profilaxia preconizada é a notificação de surtos, investigação epidemiológica, educação em higiene pessoal e eliminação sanitária de fezes (CVE, 2002). Para evitar a transmissão através do consumo de carnes contaminadas, a lavagem das carcaças com água quente e a aplicaçấo de tratamento térmico, utilizando $75^{\circ} \mathrm{C}$ por 60 segundos, é suficiente para eliminar o C. parvum, da mesma forma que o tratamento térmico utilizando 48 horas a $-3^{\circ} \mathrm{C}$ já reduz significativamente a viabilidade da infecção (Moriarty et al., 2005; Mcevoy et al., 2004). O aumento da temperatura também é efetivo para eliminar a transmissáo através do consumo de leite e da água, pois, com $71,7^{\circ} \mathrm{C}$ por 5 segundos, os oocistos de Cryptosporidium sp. se mostraram inviáveis para causar infecção (HaRp, 1996).

\section{Anisacose}

Zoonose descrita pela primeira vez em 1955, na Holanda, cujos principais agentes etiológicos são os nematoides Anisakis simplex, Pseudoterranova decipiens e Contracaecum osculatum, além de outros menos frequentes, implicados em infecçóes humanas pelo consumo de frutos do mar, crus ou mal cozidos. Normalmente, o paciente apresenta formigamento na garganta, e, em casos severos, ocorre dor abdominal e náusea devido à ação do parasita. Pode também ocorrer reação anafilática. As larvas normalmente se introduzem no trato digestivo, permanecendo entre a camada mucosa e muscular, desencadeando uma resposta imunológica que forma um granuloma em volta do parasita (Prata, 1999).

Os frutos do mar são as principais fontes de infecção do parasita para humanos. Podem estar presentes em pequenos crustáceos, peixes, invertebrados, como a lula, e até mamíferos, como as baleias, durante as fases do ciclo. Caso a evisceração não ocorra imediatamente após a captura, a larva pode se mover das vísceras para a carne do peixe, constituindo um sério risco devido à crescente popularidade do consumo de comida japonesa crua, como "sushi" e "sashimi" (Broglia, 2011), que também condiz com a alta prevalência da enfermidade no Japão (Prata, 1999).

As larvas desses parasitas são encontradas com maior frequência na carne de arenque, salmão, hadoque e bacalhau. No Brasil, as larvas de Anisakidae já foram encontradas em peixe-espada (Trichiuris lepturus), anchovas (Pomatomus saltatriz), pargos (Pagrus pagrus) (Germano, 1998) e peixe-porco (Aluterus monoceros) (Dias et al., 2010). Também foram observadas com alta prevalência $(77,35 \%)$ em jundiás (Rhamdia quelen), no Rio Grande do Sul, Brasil (Rue et al., 2010).
Entre os anos de 2002 e 2005 foram avaliados bacalhaus comercializados na cidade de Ribeiráo Preto (SP), utilizando amostras de bacalhau Porto e Zarbo eviscerados, secos e salgados. Das 11 amostras avaliadas, 64\% estavam em desacordo por possuírem larvas de nematoides da família Anisakidae, demonstrando inadequação para o consumo, apesar de a transmissão estar inviabilizada devido ao tratamento pela salga (Prado; Capuano, 2006). Em outro estudo, realizado por Pereira et al., em 2000, esses nematódeos foram encontrados em 27,3\% dos bacalhaus comerciais avaliados na capital do estado de São Paulo.

O FDA preconiza que, para ser consumido cru, todo molusco ou peixe deve, antes, ser congelado a $-35^{\circ} \mathrm{C}$ por 15 horas, ou $-20^{\circ} \mathrm{C}$ por pelo menos sete dias. $\mathrm{O}$ cozimento também é efetivo para evitar a transmissão da doença, devendo ser realizado a, no mínimo, $70^{\circ} \mathrm{C}$, segundo a OMS. Ressalva-se que a inviabilização das larvas só é feita pelas baixas e altas temperaturas, ou pela salinidade, quando atingem todas as partes do peixe.

Deve-se inspecionar visualmente toda a cavidade abdominal do pescado, para controlar o risco de transmissão de parasitas, segundo o Regulamento no 2074/2005, da Uniáo Europeia. Segundo Reino et al., em 2012, a inspeção dos intestinos dos animais à procura de larvas do parasita teve baixa eficiência, apenas sugerindo a possibilidade de infecção presente na musculatura. Porém, destaca-se a importância da persistência das larvas no fígado e nas gônadas dos animais, podendo permanecer presentes mesmo após a remoção e a lavagem dos intestinos.

Para o controle nos peixes cultivados, recomenda-se a implantação de um sistema APPCC, sendo considerado como ponto crítico de controle a etapa da produção, pois estudos já comprovaram que é possível produzir peixes que não alberguem tal parasita (Santos; Howgate, 2011), utilizando ferramentas como "Good Aquaculture Practices (GAqP)", que estabelece procedimentos para prevenção de enfermidades: $o$ AquaFRAM, capaz de avaliar e reduzir os possíveis riscos dentro do programa APPCC para fazendas de aquacultura (Soon; Baines, 2012), e o uso de Reação em Cadeia de Polimerase (PCR) em tempo real para detecçáo do agente em qualquer tipo de produto alimentício, inclusive os com elevado processamento, sendo um método rápido e de elevada sensibilidade (Herrero et al., 2011).

\section{Difilobotriose}

Enfermidade causada pelo cestódeo Diphyllobothrium latum, parasita de peixes de água doce ou salgada, que também pode acometer humanos. Pessoas infectadas apresentam anemia megaloblástica, distensão abdominal, flatulência, cólicas e diarreia durante a manifestação clínica da enfermidade. Os homens, canídeos, felídeos e os ursos são os hospedeiros definitivos desse parasita, sendo a transmissão associada ao 
consumo de larvas presentes na musculatura dos peixes, como o salmão (PraTA, 1999).

O primeiro relato de Diphyllobothrium latum no Brasil ocorreu em 2004, na Bahia, acometendo uma mulher de 29 anos que tinha consumido sushis (SANTOS; Faro, 2005). Em 2005, a Secretaria de Vigilância em Saúde do Ministério da Saúde foi notificada da ocorrência de 27 casos autóctones de Difilobotríase causada pelo Diphyllobothrium latum em São Paulo, tendo ocorrido no período de 2004 a 2005, associados à ingestáo em restaurantes japoneses.

Em 2005, foi detectado em cinco indivíduos do Rio de Janeiro que possuíam o hábito de consumir comida japonesa crua (Tavares et al., 2005), além de Brasília (DF) (Llaguno et al., 2008), Porto Alegre (RS) (MezZARi; Wiebbeling, 2008) e Ribeirão Preto (SP), onde havia histórico de consumo de peixes crus (CAPUano et al., 2007).

Para prevenir a ocorrência da enfermidade, deve-se evitar consumir pescados crus, defumados sob temperatura inadequada ou mal cozidos. $\mathrm{O}$ congelamento a $-20^{\circ} \mathrm{C}$ por sete dias é também um procedimento recomendado para inviabilizar o parasita, assegurando a proteçáo do consumidor de pratos da culinária japonesa à base de peixes crus (CVE, 2005).

\section{Triquinelose}

Enfermidade causada pelo nematódeo Trichinella spiralis, sendo zoonótica e de grande relevância para a saúde pública. Causa quadros digestivos devido à ação dos adultos presentes nos intestinos, podendo, também, apresentar nefrite, pneumonia, meningite, encefalite e miocardite, devido à migraçáo sistêmica das larvas (PEgorini et al., 2005). Está presente na lista de enfermidades de declaração obrigatória da OIE, colocando os países onde está presente em desvantagens em termos do comércio internacional de carnes devido à rejeiçáo dos produtos.
Não há relatos dessa enfermidade no Brasil, mesmo sendo realizados frequentes testes nos rebanhos suínos, cuja carne é a principal fonte de infecção na transmissão para humanos (Vieira; Ritta, 2005). Entretanto, utilizando os binômios $-25^{\circ} \mathrm{C}$ por 20 dias ou $-29^{\circ} \mathrm{C}$ por 12 dias, já é possível inviabilizar os parasitas (BrasiL, 2002). Pode ser diagnosticada nos músculos de carcaças utilizando o triquinoscópio (PegorinI et al., 2005) e pelo método da digestão artificial (MAPA, 2002).

As principais fontes de infecção para os suínos são ingestão de comidas mal cozidas, canibalismo, exposição a roedores mortos ou animais selvagens infectados.

O Brasil é considerado uma área sem risco epidemiológico, o que possibilita avanços na exportação de carnes suínas para grandes centros consumidores, como a Rússia, país que exige vários testes para detecção do parasita ou tratamentos adequados para eliminar o risco de transmissão, além de relatórios mensais feitos por fiscais federais agropecuários dos estabelecimentos sobre os resultados de análises para ocorrência de triquinelose (MAPA, 2002).

\section{CONSIDERAÇÕES FINAIS}

Por meio dos dados revisados, pode-se verificar que ainda estão presentes no Brasil importantes zoonoses parasitárias, que podem ser transmitidas através do consumo de produtos de origem animal. Essas infecçôes causam grandes prejuízos à economia nacional, por meio de prejuízos econômicos e pecuários diretos e indiretos, decorrentes da reduçáo de produtividade, perdas por condenaçôes sanitárias na etapa final das cadeias produtivas e por embargos decorrentes de exigências de centros consumidores estrangeiros; além do enorme impacto na Saúde Pública. Pode-se, ainda, afirmar que medidas profiláticas são necessárias e devem ser monitoradas em diversos pontos das cadeias produtivas no Brasil.

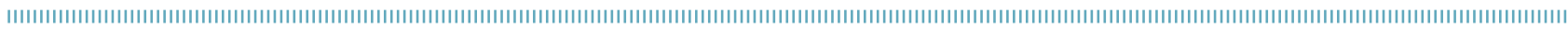

\section{REFERÊNCIAS}

ALLEPUZ, A.; NAPP, S.; PICADO, A.; ALBA, A.; PANADES, J.; DOMINGO, M.; CASAL, J. Descriptive and spatial epidemiology of bovine cysticercosis in North- Eastern Spain (Catalonia). Veterinary Parasitology, Amsterdam, v.159, p.43-48, 2009.

ALMEIDA, L.P.; MOREIRA, M.D.; REIS, D.O. Cisticercose Bovina: um estudo comparativo entre animais abatidos em frigoríficos com serviço de inspeção federal e com inspeção municipal. Higiene Alimentar, v.16, p.51-55, 2002.

ALMEIDA, L.P.; REIS, D.O.; MOREIRA, M.D.; PALMEIRA, S.B.S. Cisticercos em bovinos procedentes de minas gerais e abatidos em frigoríficos de Uberlândia - MG, no período de 1997 a 2001. Higiene Alimentar, v.20, n.139, p.40-43, 2006.
ARAUJO, F.A.P.; SOUZA, W.J.S. Prevalência de toxoplasmose em suínos da região de Erechim (RS), detectados pela Imunofluorescência Indireta. Congresso Panamericano de Ciências Veterinárias, v. 15, p.335, 1996.

BRASIL, MAPA. Ministério da Agricultura, Pecuária e Abastecimento. Circular 129/2002/DCI/DIPOA. Brasilia: Departamento de Inspeção de Produtos de Origem Animal, 2002.

BRASIL. MAPA. Ministério da Agricultura, Pecuária e Abastecimento. RIISPOA - Regulamento da Inspeção Industrial e Sanitária dos Produtos de Origem Animal. Brasília, 1952.

BRASIL. MINISTÉRIO DA SAÚDE. Fundação Nacional da Saúde. Surto de toxoplasmose no município de Santa Isabel do Ivaí Paraná. Boletim eletrônico epidemiológico, v.3, p.1-9, 2002. 
BRASIL. MINISTÉRIO DA SAÚDE. Secretaria de Vigilância em Saúde. Manual integrado de vigilância, prevenção e controle de doenças transmitidas por alimentos. 2010. p.11.

BRASIL. MINISTÉRIO DA SAÚDE. Doenças Infecciosas e Parasitárias - Guia de Bolso, 8a ed. Brasília, 2010.

BRASIL. MINISTÉRIO DA SAÚDE. Fundação Nacional da Saúde. Surto de Toxoplasmose no Município de Santa Isabel do Ivaí. Boletim eletrônico epidemiológico, v.7, p. 1-3, 2002. Disponível em: http://portal.saude.gov.br/portal/arquivos/pdf/ano02_ nO7_surto_toxoplasmose_per.pdf. Acesso em: 13 jun. 2012.

BRASIL. MINISTÉRIO DA SAÚDE. Fundação Nacional da Saúde. Surto intrafamiliar de toxoplasmose, Santa Vitória do Palmar-RS, julho de 2005. Boletim eletrônico epidemiológico, n.3, 2006. Disponível em: http://portal.saude.gov.br/portal/arquivos/pdf/ boletim_03_06.pdf, Acesso em: 13 jun. 2012.

BRASIL. MINISTÉRIO DA SAÚDE. Fundação Nacional da Saúde. Surto de toxoplasmose adquirida, Anápolis-GO, Fevereiro de 2006. Boletim eletrônico epidemiológico, n.8, 2007. Disponível em: http://portal.saude.gov.br/portal/arquivos/pdf/ano07_n08_ toxopl_adquirida_go.pdf. Acesso em: 13 jun. 2012.

BONAMETTI, A.M.; PASSOS, J.N.; SILVA, E.M.K.; BORTOLIERO, A.L., Surto de toxoplasmose aguda transmitida através da ingestão de carne crua de gado ovino. Revista Sociedade Brasileira Medicina Tropical, v.30, n.1, p.21-25, 1997.

BOONE, I.; THYS, E.; MARCOTTY, T.; BORCHGRAVE, J. de; DUCHEYNE, E.; DORNY, P. Distribution and risks factors of bovine cysticercosis in Belgian dairy and mixed herds. Preventive Veterinary Medicine, v.82, p.1-11, 2007.

BROGLIA, A.; KAPEL, C. Changing dietary habits in changing world: emerging drivers for the transmission of foodborne parasitic zoonoses. Veterinary Parasitology, v.182, p.2-13, 2011.

CABARET, J.; GEERTS, S.; MADELINE, M.; BALLANDONNE, C.; BARBIER, $D$. The use of urban sewage sludge on pastures: the cysticercosis threat. Veterinary Research, Paris, v.33, p.575-597, 2002.

CAPUANO, D.M.; OKINO, M.H.T.; MATTOS, H.R.M., TORRES, D.M.A.G.V. Difilobotríase: relato de caso no município de Ribeirão Preto, SP, Brasil. Revista Brasileira de Análises Clínicas, v.39, n.3, p. 163-164, 2007.

CASTRO, A.P.B. Implicações da toxoplasmose na saúde pública. 2006. 45f. Dissertação (Mestrado) - Faculdade de Medicina Veterinária e Zootecnia, Universidade Estadual Paulista, Botucatu, 2006.

CHOI, W.Y.; NAM, H.W.; KWAK, N.H.; HUH, W.; KIM, Y.R.; KANG, M.W.; CHO, S.Y.; DUBEY, J.P. Foodborne outbreaks of human toxoplasmosis. Journal of Infectious Diseases, v.175, p.1280$1282,1997$.

COSTA, R.F.R.; SANTOS, I.F.; SANTANA, A.P.; TORTELLY, R.; NASCIMENTO, E.R.; FUKUDA, R.T.; CARVALHO, E.C.Q.; MENEZES, R.C. Caracterização das lesões por Cysticercus bovis na inspeção post-mortem de bovinos, pelo exame macroscópico, histopatológico e pela reação em cadeia de polimerase (PCR). Pesquisa Veterinária Brasileira. v.32, n.6, p.477-484, 2012.
CVE. Manual das doenças transmitidas por alimentos. Crypstosporidium parvum / Criptosporidiose, 2002. Disponível em: ftp://ftp.cve.saude.sp.gov.br/doc_tec/hidrica/ifnet_cryptos. pdf. Acesso em: 8 jun. 2012.

CVE. Manual das doenças transmitidas por alimentos. Diphyllobothrium spp/Difilobotríase. 2005. Disponível em: http://www.cve.saude.sp.gov.br/htm/hidrica/IF_Diphy.htm. Acesso em: 8 jun. 2012.

DA SILVA, A.V.; MENDONÇA, A.O.; PEZERICO, S.B.; DOMINGUES, P.F.; LANGONI, H. Genotipagem de cepas de Toxoplasma gondii isoladas de linguiças frescas preparadas com carne suína. Arquivo Ciência Veterinária Zoologia, v.7, n.2, p.99, 2004.

DDTHA/CVE/SES-SP, 2002. Matriz de Surtos 2001. In: Informe NET DTA. Disponível em: http://www.cve.saude.sp.gov.br <Dados Estatísticos > <Surtos>. Acesso em 03 jun 2012.

DIAS, F.J.E.; CLEMENTE, S.C.S.; KNOFF, M. Nematoides anisaquídeos e cestoides Trypanorhincha de importância em saúde pública em Aluterus monoceros (Linnaeus, 1758) no Estado do Rio de Janeiro, Brasil. Revista Brasileira de Parasitologia Veterinária, v.19, n.2, p.94-97, 2010.

DUBEY, J.P. A review of toxoplasmosis in cattle. Veterinary Parasitology, v.22, p.177-202, 1986.

DUBEY, J.P. Toxoplasmosis - a waterborne zoonosis. Veterinary Parasitology, v.126, p.57-72, 2004.

DUBEY, J.P.; MILLER, N.L.; FRANKEL, J.K. The Toxoplasma gondii oocyst from cat feces. Journal of Experimental Medicine, v.132, p.636-662, 1970.

DUBEY, J.P.; MURREL, K.D.; FAYER, R. Persistence of encysted T. gondii in tissues of pigs fed oocysts. American Journal of Veterinary Research, v.45, p.1941-1943, 1984.

DUTRA, L.H.; GIROTTO, A.; VIEIRA, R.F.deC.; VIEIRA, T.S.W.J.; ZANGIROLAMO, A.F.; MARQUÊS, F.A.C.; HEADLEY, S.A.; VIDOTTO, O. The prevalence and spatial epidemiology of cysticercosis in slaughtered cattle from Brazil. Semina: Ciências Agrárias, Londrina, v.33, n.5, 2012.

ESMERINI, P. Isolamento e detecção molecular de Toxoplasma gondii (Nicolle\&Manceaux, 1909) de moluscos bivalves marinhos comercializados no mercado de peixes do município de Santos no estado de São Paulo. 2009. Dissertação (Mestrado) - Universidade de São Paulo. São Paulo, 2009.

FLÜTSCH, F.; HEINZMANN, D.; MATHIS, A.; HERTZBERG, H.; STEPHAN, R.; DEPLAZES, P. Case-control study to identify risk factors for bovine cysticercosis on farms in Switzerland. Parasitology, v.135, p.641-646, 2008.

FREITAS, J.A.; OLIVEIRA, J.P.; RAMOS, O.S.; ISHIZUKA, M.M. Frequência de anticorpos anti-Toxoplasma gondii em suínos abatidos sem inspeção em Belém. Arquivo Brasileiro Medicina Veterinária e Zootecnia, v.6, p.1230-1232, 2009.

FUKUDA, R.T., PRATA, L.F. Contribuição ao estudo da epidemiologia da cisticercose bovina na região administrativa de Barretos. Aspectos ambientais e econômicos. 2003. Tese (Doutorado) Universidade Estadual Paulista. Jaboticabal, 2003. 
GERMANO, P.M.L.; GERMANO, M.I.S. Anisaquíase: zoonose parasitária emergente no Brasil? Higiene Alimentar, v. 12, n.54, p.26-35, 1998.

HARP, J.A.; FAYER, R.; PESCH, B.A.; JACKSON, G.J. Effect of pasteurization on infectivity of Cryptosporidium parvum oocists in water and milk. Applied and Environmental Microbiology, v.62, n.8, p.2866-2868, 1996.

HARPER, C.M.; COWELL, N.A.; ADAMS, B.C.; LANGLEY, A.J.; WOHLSEN, T.D. Outbreak of Cryptosporidium linked to drinking unpasteurized milk. CDI Quarterly Report, v.26, n.3, p.449450, 2002.

HERRERO, V.; VIEITES, J.M.; ESPINEIRA, M. Detection of anisakids in fish and seafood products by real-time PCR. Food Control, v.22, p.933-939, 2011.

HILL, D.E.; CHIRUKANDOTH, S.; DUBEY, J.P. Biology and epidemiology of Toxoplasma gondii in man and animals. Animal Health Research Reviews, v.6, n. 1, p.41-61, 2005.

HIPOLITO, G.C.; FERNANDO, M.H.; JOSE ANTONIO, C.H. Cryptosporidium contamination in harvesting areas of bivalve mollusks. Journal of Food Protection, v.69, n. 1, p.185-190, 2006.

IBGE. Indicadores IBGE - Estatística de Produção Pecuária. Março de 2012. Disponível em: http://www.ibge.gov.br/home/ estatistica/indicadores/agropecuaria/producaoagropecuaria/ abate-leite-couro-ovos_201104_publ_completa.pdf. Acesso em: 7 jun. 2012.

JONES, J.L.; DARGELAS, V.; ROBERTS, J.; PRESS, C.; REMINGTON, J.S.; MONTOYA, J.G. Risk factors for Toxoplasma gondii infection in the United States. Clinical Infectious Diseases, v.49, p.878-884, 2009.

JONES, J.L.; DUBEY, J.P. Foodborn toxoplasmosis. Clinical Infectious Diseases Advance Access. 2012. Disponível em: http://www.cid. oxfordjournals.org/cgi/pmidlookup?view=long\&pmid=22618566. Acesso em: 12 jun. 2012.

KIJLSTRA, A.; JONGERT, E. Toxoplasma-safe meat: close to reality? Trends in Parasitology, v.25, n. 1, p.18-22, 2009.

KYVSGAARD, N.C.; ILSOE, B.; WILLEBERG, P.; NANSEN, P.; HENRIKSEN, S.A. (1991). A case-control study of risk factors in light Taenia saginata cysticercosis in Danish cattle. Acta Veterinaria Scandinavica, v.32, p.243-252, 1991.

LIMA, R.S.; FRANÇA, E.L.; FRANÇA, A.C.H.; FERRARI, C.K.B. Prevalência de cisticercose bovina e conhecimento sobre a doença em 20 municípios do estado do Mato Grosso. Revista Panorâmica Multidisciplinar, v.12, p.42-60, 2011.

LLAGUNO, M.M.; ESCALANTE, J.C.; WAIKAGUL, J.; FALEIROS, A.C.G.; CHAGAS, F.; CASTRO, C. Diphyllobothrium latum infection in a non-endemic country: case report. Revista da Sociedade Brasileira de Medicina Tropical, v.41, n.3, p.301-303, 2008.

LUCIANO, D.M.; MENEZES, R.C.; FERREIRA, L.C.; NICOLAU, J.L.; NEVES, L.B.; LUCIANO, R.M.; DAHROUG, M.A.A.; AMENDOEIRA, M.R.R. Occurrence of anti-Toxoplasma gondii in cattle and pigs slaughtered, State of Rio de Janeiro. Revista Brasisleira Parasitologia Veterinaria, v.20, n.4, p.351-353, 2011.
MARANA, E.R.M.; NAVARRO, I.T.; VIDOTTO, O.; FREIRE, R.L.; LOTT, R. Ocorrência de anticorpos anti-Toxoplasma gondii em bovinos de corte, abatidos em matadouros do Norte do Estado do ParanáBrasil. Semina: Ciências Agrárias, v. 15, n. 1, p.38-40, 1994.

MCEVOY, J.M.; MORIARTY, E.M.; DUFFY, G.; SHERIDAN, J.J.; BLAIR, I.S.; MCDOWELL, D.A. Effect of a commercial freeze/ tempering process on the viability of Cryptosporidium parvum oocists on lean and fat beef trimmings. Meat Science, v.67, n.4, p.559-564, 2004.

MECCA, J.N.; MEIRELES, R.L.; ANDRADE JR., H.F. Quality control of Toxoplasma gondii in meat packages: standardization of an ELISA test and its use for detection in rabbit meat cuts. Meat Science, v.88, p.584-589, 2011.

MEIRELLES, L.R.; GALISTEO JR., A.J.; ANDRADE JR., H.F. Serological survey of antibodies to Toxoplasma gondii in food animals from São Paulo state, Brazil. Brazilian Journal of Veterinary Research and Animal Science, v.40, p.267-271, 2003.

MEZZARI, M.D.A.; WIEBBELING, A.M.P. Diphyllobothriasis in Southern Brazil. Clinical Microbiology Newsletter, v.30, p.28-29, 2008.

MORIARTY, E.M.; DUFFY G.; MCEVOY, J.M.; CACCIO, S.; SHERIDAN, J.J.; MCDOWELL, B.; BLAIR, I.S. The effect of thermal treatments on the viability and infectivity of Crypstosporidium parvum on beef surfaces. Journal of Applied Microbiology, v.98, p.618-623, 2005.

NAVARRO, I.T.; VIDOTTO, O.; GIRALDI, N.; FREIRE, R.L. Toxoplasma gondii : isolamento a partir de carne e cérebro de suínos comercializados na região de Londrina- PR. Semina: Ciências Agrárias, v.13, n.1, p.32-34, 1992.

OIE, WORLD ORGANIZATION FOR ANIMAL HEALTH. OIE Terrestrial Manual Code, p.1216-1226. 2008. Disponível em: http://www. oie.int/fileadmin/Home/eng/Health_standards/tahm/2.09.05_ CYSTICERCOSIS.pdf. Acesso em: 4 jun. 2013.

OPSTEEGH, M.; LANGELLAR, M; SPRONG, H.; HARTOG, L.; CRAEYE, S.; BOKKEN, G.; AJZENBERG, D.; KIJLSTRA, A.; GIESSEN, J.V.D. Direct detection and genotyping of Toxoplasma gondii in meat samples using magnetic capture and PCR. International Journal of Food Microbiology, v.39, p. 193-201, 2010.

PEGORINI, P.L.; SOUZA, V.K.; PEREIRA, A.P. Trichinella spiralis. Higiene Alimentar, v.29, n.135, 2005.

PEREIRA, A.D.; ATUI, M.B.; TORRES, D.M.A.G.V.; MANGINI, A.C.; ZAMBONI, C.Q. Incidência de parasitos da família Anisakidae em bacalhau (Gadus morhua) comercializado no Estado de São Paulo. Revista do Instituto Adolfo Lutz, v.59, p.45-49, 2000.

PINTO, L.B.; CARLI, C.M.; RODRIGUES, B.A. Prevalência de toxoplasmose na medicina veterinária e sua importância como zoonose: revisão. Veterinária em Foco, v.7, n. 1, p.36-45, 2009.

PRADO, S.P.T.; CAPUANO, D.M. Relato de nematoides da família Anisakidae em bacalhau comercializado em Ribeirão Preto, SP. Revista Sociedade Brasileira de Medicina Tropical, v.39, n.6, p.580-581, 2006.

PRATA, L.F. Manual de enfermidades transmitidas por alimentos. Jaboticabal: FUNEP. 1999. 
REINO, M.L.; GONZALEZ, A.F.; VELLO, C.; OUTEIRINO, L.; PASCUAL, $\mathrm{S}$. The accuracy of visual inspection for preventing risks of Anisakis spp. infection in unprocessed fish. Food Control, v.23, p.54-58, 2012.

REY, L. Bases da Parasitologia Médica. $2^{\mathrm{a}}$ ed. Rio de Janeiro: Guanabara Koogan. 2002.

ROSSI, G.A.M.; GRISÓLIO, A.P.R.; PRATA, L.F.; BÜRGER, K.P.; HOPPE, E.G.L. Situação da cisticercose bovina no Brasil. Semina: Ciências Agrárias, v.35, n.2, p.927-938, 2014.

RUE, M.L.; CEOLIN, L.V.; GABRIEL, C.C.; BALDISSEROTTO, B.; BECKER, A.G.; ALMEIDA, F.M.; JUNIOR, J.P. Risco de zoonose por parasitos do trato digestores de jundiás (Rhamdia quellen) coletados em reservatórios de água da região central do Rio Grande do Sul. Revista Saúde, Santa Maria, v.36, n.2, p.79-81, 2010.

SANTOS, C.A.M.L.; HOWGATE, P. Fishborne zoonotic parasites and aquaculture: a review. Aquaculture, v.318, p.253-261, 2011.

SANTOS, F.L.N.; FARO, L.B. The first confirmed case of Diphyllobothrium latum in Brazil. Memorial Instituto Oswaldo Cruz, v.100, p.585-586, 2005.

SANTOS, I.F.; MANO, S.B.; TORTELLY, R.; SANTOS, M.L.S.; SILVA, D.A.S. Estudo da localização do Cysticercus bovis em corações de bovinos abatidos sob inspeção. Revista Higiene Alimentar, v. 15, n.89, p.41- 43, 2001

SANTOS, J.M.G.; BARROS, M.C.R.B. Endoparasitas de importância no comércio da carne. Revista do Agronegócio e Meio Ambiente, v.2, n. 1, p.21-39, 2009.

SCANDRETT, B.; PARKER, S.; FORBES, L.; GAJADHAR, A. DEKUMYOY, P.; JITRA, W.; HAINES, D. Distribuition of Taenia saginata cysticerci in tissues of experimentally infected cattle. Veterinary Parasitology, Amsterdam, v. 164, p.223-231, 2009.

SILVA, C.G.M.; ANDRADE, S.A.C.; STAMFORD, T.L.M. Ocorrência de Cryptosporidium spp. e outros parasitas em hortaliças consumidas in natura, no Recife. Ciência em Saúde Coletiva, v.10, p.63-70, 2005.

SMITH, H.V.; NICHOLS, R.A.B. Cryptosporidium: detection in water and food. Experimental Parasitology, v.124, p.61-79, 2010.

SOON, J.M.; BAINES, R.N. Aquaculture farm food safety and diseases risks assessment (AquaFRAM): development of a spreadsheet tool for salmons farms. Aquacultural Engineering, v.49, p.35-25, 2012.

SWEENY, J.P.A.; RYAN, U.M.; ROBERTSON, I.D.; JACOBSON, C. Cryptosporidium and Giardia associated with reduced lamb carcase productivity. Veterinary Parasitology, v.182, p.127-139, 2011.

TAVARES, L.E.R.; LUQUE, J.L.; BOMFIM, T.C.B. Human diphyllobothriasis: reports from Rio de Janeiro, Brazil. Revista Brasileira Parasitologia Veterinária, v. 14, n.2, p.85-87, 2005.

TENTER, A.M., HECKEROTH, A.R.; WEISS, L.M. Toxoplasma gondii: from animals to humans. International Journal of Parasitology, v.30, p.217-58, 2000.

UENO, T.E.H. Prevalência das infecções por Toxoplasma gondii e Neospora caninum em matrizes e reprodutores ovinos de rebanhos comerciais do Distrito Federal. 2005. Tese (Doutorado) - Faculdade de Medicina Veterinária e Zootecnia, Universidade Estadual Paulista. Botucatu, 2005.

VALLE, E.R. Manual de orientações: BrazilianGap - Boas práticas agropecuárias - Bovinos de corte. $2^{\mathrm{a}}$ ed. Embrapa Gado de Corte, 2011.

VIEIRA, M.I.B.; RITTA, I.P.D. Apostila Curso Teórico-Prático de Trichinella spiralis. Universidade de Passo Fundo, 2005.

VILLENA, I.; DURAND, B.; AUBERT, D.; BLAGA, R.; GEERS, R.; THOMAS, M.; PERRET, C.; ALLIOT, A.; BINNET, S.E.; THEBAULT, A.; BOIREAU, P.; HALOS, L. New strategy of the survey of Toxoplasma gondii in meat for human consumption. Veterinary Parasitology, v.183, p.203-208, 2012 